\title{
К.П.ГЛАЗКОВ \\ АРХЕОЛОГИЯ ПЕРИФЕРИИ: ШЕСТЬ ЛЕТ СПУСТЯ
}

Глазков Константин Павлович ${ }^{1}$, кандидат социологических наук, старший преподаватель кафедры методов сбора и анализа социологической информации НИУ ВШЭ; Российская Федерация, 101000, Москва, ул. Мясницкая, д. 20, тел.: +79778455251

E-mail: glazkov.konst@gmail.com

В декабре 2013 года на Московском урбанистическом форуме (МУФ) было представлено комплексное исследование, посвященное окраинам Москвы, - «Археология периферии». Исследование проводилось по шести направлениям: общество, политика, архитектура, культура, экономика, данные. Исследовательские команды отмечали значительный потенциал периферийных районов города, которые на тот момент были «спящими». Эти территории оставались лишь градосоставляющими, но не градообразующими. При этом критики данного проекта говорили о том, что в нем недостаточно раскрыта связь центральных и периферийных районов, которая, возможно, пролила бы свет на причины слабой реализации потенциала периферийных территорий.

Прошло шесть лет. Москва бурно развивается. Уже три года функционирует Московское центральное кольцо (МЦК), полностью пролегающее по периферийным районам. Осуществляется ввод масштабной транспортной системы Московских центральных диаметров (МЦД), которая расположится за пределами Москвы. Открываются новые ветки метро, реализуются проекты по благоустройству («Моя улица», «Мой район»), на подходе активная фаза реновации. Интересно вспомнить «Археологию периферии», чтобы оценить вектор развития, сложившийся с тех пор. Мы решили обсудить с авторами сборника перемены, происходящие в Москве, пытающейся найти баланс между центром и периферией.

Нам удалось пообщаться с восьмью экспертами, которые в рамках работы над сборником отвечали за разные исследовательские направления. В результате мы обсудили вопросы границ Москвы, представление о московской периферии, задались вопросами нового административного расширения города и присоединения Новой Москвы, ролью МКАД в современном городе, перспективами реновации и возможностями проекта «Мой район» по формированию полицентричной городской среды, воздействием МЦК на периферийные территории, ожиданиями от запуска МЦД, а также тем, чем могла бы быть «Археология периферии 2.0».

Ключевые слова: центр; периферия; агломерация; Москва; МКАД; МЦК; МЦД

Цитирование: Глазков К.П. (2019) Археология периферии: шесть лет спустя//Городские исследования и практики.

T. 4. № 2. C. 86-103. DOI: https://doi.org/10.17323/usp42201986-103

\section{Периферия: lost in translation}

$\mathrm{H}$ ачиная разговор об отношениях центра и периферии, необходимо признать, что они остаются весьма запутанными. Собственно, одно из критических замечаний [Глазков, 2014] в адрес «Археологии периферии» касалось недостаточного учета аспектов взаимосвязи так называемого центра с территорией, выделенной в качестве периферии.

Последняя, будучи изначально исключительно геометрическим понятием, обозначающим удаленность от центра применительно к разномасштабным географическим объектам, все больше обрастает социальным контекстом. Воспринятый социальными науками феномен периферии обретает характеристики процессов, описывающих ее (вос-)производство посредством социальных отношений и их пространственных воплощений [Kühn, 2015, p. 367]. Некогда ярлык для сельской местности или даже целого региона, как, например, в случае Восточной Германии [Lang, 2012], периферия - а точнее сказать, nериферизация [Herrschel, 2011] - расширяет диапазон применения термина, охватывая отношения как между странами, так и локаль-

1 Научные интересы: микросоциология, поведение в публичных местах, геолокационные сервисы. 
ными соседствами. В такой трактовке периферизация становится все более синонимичной термину «маргинализация» [Danson, De Souza, 2012], подразумевая низкий уровень развития территории, ее неконсистентную интеграцию в городскую ткань, отсутствие инноваций, стигматизацию и бедность населения, организованную зависимость местных органов управления от центра и неспособность самостоятельного формирования повестки развития. Одновременно со структурными факторами, позволяющими центру привлекать население, экономическую активность и инфраструктурные функции [Lang, 2012, p. 1750], отношения между центром и периферией определяются дискурсивно, отражая сложившуюся на периферийных территориях политическую беспомощность, культуру принятия и сообщества бездействия [Blowers, Leroy, 1994, p. 204].

Динамичный характер (вос-)производства периферии, который рассматривался А.Э.Гутновым в рамках модели «каркас - ткань» [Гутнов, 1982], остро ставит вопрос о границах, в пределах которых существуют одни центры и их периферии и за пределами которых начинаются другие. При этом границы способны выполнять не только разделительные и барьерные функции, но и контактные, тем самым обретая собственное содержание и осуществляя инверсию «центр $\leftrightarrow$ граница» [Каганский, 2015, c. 12]. Тем более примечательно, что на границах способны формироваться так называемые окраинные города [Garreau, 1991], или постсубурбии [Теаford, 1997; Jonas, 2013], которые обретают самостоятельность городского центра, собственную идентичность и функциональную самодостаточность. Тем самым они противопоставляют себя «центральному городу» и его пригородам, ставя под сомнение модель центростремительного роста агломераций [Голубчиков, Махрова, 2010, с. 63].

В случае с Москвой дополнительные трудности для определения периферии создает cmoличный статус города. «Столичный город» и «центральный город» необязательно одно и то же, но в Москве эти позиции накладываются и взаимно усиливают друг друга. Символическая функция столицы заключается в репрезентации «большого пространства государства - в пространстве столиц» [Россман, 2013]. «Так, в Москве, например, есть районы, которые до сих пор воспроизводят в названиях улиц и проспектов физическую географию целых республик или регионов СССР (например, Крым или Украину на юге Москвы)» [Там же]. Тем самым внутренние территории не соответствуют самим себе, а являются колониальным инструментом для сборки имперских территорий [Глазков, Гнилорыбов, 2017].

Важно отметить, что, по мнению немецкого историка Андреаса Даума [Daum, 2010], в символические и интеграционные функции столиц необязательно входит функция экономической активности и роста. Тем не менее в поисках окраинных городов и границ агломераций основной исследовательской категорией продолжает оставаться трудовая мобильность, которая, с одной стороны, позволяет обнаруживать полицентричную структуру московской агломерации [Махрова, Кириллов, 2016], но, с другой стороны, может препятствовать описанию пространственной структуры полицентричной Москвы [Новиков и дp., 2016]. Последняя трактовка противопоставлена идее определения городских субцентров через выявление концентрации мест приложения труда [Fujita, Ogawa, 1982] и исходит из того, что труд перестает быть единственным фактором притяжения, а ключевым индикатором центра является поточность. Другими словами, «истинными городскими субцентрами являются центры „добровольного посещения“». Эти места, в отличие от центров концентрации приложения труда, привлекают людей объектами торговли, обслуживания, культуры и отдыха. Такие места генерируют устойчивые потоки людей, и «оборот» их посещаемости в разы выше, чем в центрах трудоустройства [Новиков и др., 2016, с. 4].

Можно заметить, что принятие какого-либо одного индикатора в качестве основного критерия центральности навязывает специфическую картину того, что считать центром и периферией, а также определенный масштаб рассмотрения их отношений. В случае московской агломерации многие из этих вопросов обретают практическое значение. Например, проблема определения границ «реального» города, который образуется в результате сращивания Москвы со своими ближними пригородами. В результате чего «ближний пояс подмосковных районов буквально сливается с Москвой, а ряд его городов теснее интегрируется в структуру столицы, чем некоторые районы самой Москвы» [Махрова, Нефедова, Трейвиш, 2012, с. 8]. Не менее важен и постоянно расширяющийся ареал трудовой мобильности, который за счет скоростного железнодорожного сообщения отодвинул «изохрону двухчасовой транспортной доступности Москвы на границу области и далее», после чего «практически уже все Подмоско- 
вье стало ее пригородной зоной» [Там же]. В условиях продолжающегося наращивания связей между Москвой и Московской областью внутренняя периферия города, находящаяся между ТТК и МКАД, продолжает оставаться незамеченной. Задачу осмысления этой территории ставил перед собой и сборник «Археология периферии». Спустя шесть лет имеет смысл вновь обратиться к этой проблеме, чтобы понять, что делает эту территорию столь загадочной, а саму периферию - столь неуловимой.

\section{Состав экспертов:}

Вендина Ольга Ивановна, к. г. н., ведущий научный сотрудник Лаборатории геополитических исследований Института географии РАН

Каганский Владимир Леопольдович, к. г. н., старший научный сотрудник отдела физической географии и проблем природопользования Института географии РАН

Летуновская (Серова) Екатерина, сооснователь и вице-президент компании Habidatum

Нефедова Татьяна Григорьевна, д. г. н., главный научный сотрудник отдела социально-экономической географии Института географии РАН

Новиков Алексей Викторович, к. г. н., сооснователь и президент компании Habidatum

Острогорский Александр, архитектурный критик, преподаватель Архитектурной школы МАРШ и магистратуры «Прототипирование городов будущего» НИУ ВШЭ

Ревзин Григорий Исаакович, кандидат искусствоведения, профессор факультета городского и регионального развития НИУ ВШЭ

Трейвиш Андрей Ильич, д. г. н., главный научный сотрудник отдела социально-экономической географии Института географии РАН

\section{Где заканчивается Москва?}

Обсуждая с экспертами отношение центра и периферии, мы постоянно сталкиваемся с противопоставлением аналитического и объективного характера выделения периферии. С одной стороны, никакой объективно существующей московской периферии не существует, она является лишь аналитической конструкцией, позволяющей с определенной степенью условности схватывать недоступный для описания феномен, который к тому же постоянно норовит ускользнуть в играх с масштабом. Если мы принимаем такое определение, то административные границы субъектов могут выступать в качестве сносного подспорья для различения центра и периферии.

O. Вендина: Центр и периферия - это категории анализа. Исследователи, как правило, выделяют множество промежуточных позиций, подчеркивают, что у каждого центра есть «своя» периферия, а у каждой периферии «свои» центры. Есть и другие возможности описания центро-периферийных отношений, например, столица - провинция - глубинка захолустье. <...> Порой и достаточно грубое административно-территориальное деление как фактор, организующий жизнь общества, бывает полезным для такого анализа. <...>

Периферийность всегда определяется относительно центра. По мере удаления от точки, которую мы принимаем за центр, все остальное превращается в периферию. Конечно, это упрощенное представление, требующее уточнения и учета позиционных выгод или недостатков местоположения. Еще один фактор - игра масштабами. Мы можем рассматривать Москву как город с определенными административными границами, центром и окраинами, тогда окраины окажутся периферией. Но если мы взглянем на Москву «сверху» как на столицу страны или рассмотрим менее масштабные отношения Москвы и Московской области, то определение «центр» будет относиться к городу в целом. Станет заметно, что его граница, которая в другой системе координат была периферией, является зоной взаимодействия двух разных субъектов, одновременно играя роль барьера и контактной зоны.

Идея «Археологии периферии» находится в рамках этого подхода. Анонсируемое в сборнике «открытие» периферии, или, как ее ласково называли исследовательские команды, «панельного бублика», в каком-то смысле является результатом аналитической игры, в рамках которой участникам команд были заданы четко очерченные границы периферии. 
A. Острогорский: Я бы так утверждал, что это была абсолютно неизвестная реальность, которая впервые была таким образом предъявлена. Все, кто был в рабочих командах, занимались этими же территориями, но в каких-то своих проектах и моделях. Идея выделить «панельный бублик», определить, что есть город от ТТК и до МКАД, является абсурдом. Но сама эта позиция поставила всех участников перед игровой механикой этого исследования: давайте представим, что есть такая штука «без центра внутри», и все дисциплины оказались перед этим вызовом. Таким образом сформировалось пространство, которого не было, это то, что я называю открытием.

С другой стороны, аналитически выделенная территория между ТТК и МКАД не является чьей-то выдумкой. Выбор «панельного бублика» обусловлен обстоятельствами, в которых пребывает эта территория, испытывающая двойную периферизацию - и со стороны центра, и со стороны области.

O. Вендина: Теперь о «панельном бублике». Его промежуточное положение между центром города и кольцевой автодорогой делает его дважды периферийным. Географически он расположен центральнее, но позиционно лишен многих экономических и логистических преимуществ, обладает меньшим разнообразием возможностей, чем следующие за ним урбанизированные пространства, примыкающие к МКАД.

Таким образом, в узком смысле периферия является следствием сочетания высокой плотности населения и функциональной рыхлости, которое делает эту территорию уникальной, а решение ее проблем - самым значимым проектом для городского планирования в Москве.

А. Новиков: Дело в том, что Москва - один из самых рыхлых и одновременно самых плотных городов мира. Такое положение дел толкает человека к использованию автомобиля и снижает уровень шаговой доступности товаров и услуг повседневного спроса. Рыхлость города нарастает к спальной периферии - прежде всего в связи с застройкой микрорайонного типа. То есть там, где больше всего народу, там меньше всего услуг - они просто не «садятся» в такой тип застройки, потому что пешеходный поток в микрорайоне «рассыпается», отдельных ручейков для малого и среднего бизнеса не хватает. А житель спального района предпочитает сесть в автомобиль и уехать из этого места в центр города или торговый молл, чтобы приобрести там все необходимое. Спальные районы - рыхлое пространство, плохо насыщенное коммерческими функциями, с узким спектром функционального разнообразия. При этом там огромная плотность населения.

Таким образом, рассмотрение специфики этой территории становится невозможным без учета ее связей не только с центром, но и с Московской областью, а точнее с тем, что административно ею является. Помимо Московской области, московская агломерация очевидным образом включает те территории, которые входят в состав Москвы, но находятся за пределами МКАД (анклавы), а также территории Новой Москвы, присоединенные в 2012 году. Административное границы слабо передают сложившиеся функциональные связи между субъектами, тем самым вынуждая находить теоретические эквиваленты для обозначения того, что входит в состав Москвы. Одним из таких эквивалентов является понятие «реальный город» [Махрова, Нефедова, Трейвиш, 2012], которое, в отличие от «агломерации», передает не маятниковые трудовые мобильности, а расширение города за счет прилегающих территорий.

T. Нефедова: Эта идея [реального города] возникла у нас совместно с А.И. Трейвишем и А.Г. Махровой. В 2012 году мы опубликовали статью о московском мегалополисе. Когда говорят о зоне влияния Москвы, обычно речь идет о московской агломерации. Наши исследования показывают, что эта зона гораздо больше и охватывает значительную территорию, включающую многие районы соседних с Московской областей, испытывающих прямое экономическое влияние Москвы. А благодаря отходникам и дачникам - еще более значительную территорию центра России.

Мы пытались выделить разные функциональные зоны вокруг Москвы. Формально Москва до последнего расширения заканчивалась МКАД с небольшими выступами за нее. Но если 
смотреть на характер застройки и плотность населения, то большинство районов Московской области, прилегающие к МКАД с внешней стороны, уже тогда представляли собой далеко не сельскую местность, даже за пределами больших подмосковных городов, таких как Мытищи, Химки и др. Поэтому мы пытались выделить зону с наиболее высокой плотностью населения, значительной долей многоэтажной застройки, где большинство жителей работают в Москве, хотя и живут за ее официальными границами. Мы назвали ее «реальный город». Получилась такая «корона» вокруг Москвы, которая все последние годы расплывалась по принципу «масляного пятна» с выплесками вдоль магистралей. В этом реальном городе за МКАД люди активно покупают квартиры в многоэтажках, причем не только дальние мигранты, но и москвичи.

Следующая зона - московская агломерация, которая определяется двухчасовой транспортной доступностью от столицы. Она почти совпадает с границей Московской области с некоторыми отклонениями. Это зона интенсивных трудовых и дачно-рекреационных перемещений. Но когда начинаешь изучать дачников, то выясняется, что ареалы дачных и садовых товариществ москвичей и жителей больших городов Московской области давно уже вышли далеко за ее пределы в соседние регионы. Формируется обширная зона летнего «расползания» москвичей и жителей МО радиусом 200-300 км от Москвы.

Радикально иная теоретическая позиция заключается в противопоставлении понятий «периферия» и «провинция», как это делает В. Каганский [1998]. В такой трактовке периферия не входит в состав города, так как это вспомогательная территория без собственной идентичности и самобытности. Провинция, напротив, обладает идентичностью, входит в состав города, имеет свое специфическое функциональное наполнение, в том числе свойства центральности. Исходя из этого различения, мы, вслед за Каганским, приходим к парадоксальному выводу: бо́льшая часть территорий Москвы, за исключением небольшого центра, не является городом, а остается безликой периферией.

В. Каганский: Не разделяю точку зрения, что внутри города должна находиться периферия. Я вообще не разделяю схему «центр - периферия». В своих работах я развиваю четырехчастную схему: центр - периферия - провинция - граница.

В этом смысле в городе как полноценном ландшафте вообще практически нет периферии или она носит временный характере. И та зона, которая названа «бубликом», являясь периферией, в нормальном городе будет провинцией. Периферией будут внешние городские угодья, которые не могут быть размещены в городе в силу их технологии и масштаба например, дачи и аэропорты.

А внутренней периферии в городе не должно быть - это дефицит городского начала. В этом смысле Москва не вполне является городом, потому что откартированное выражение «поехать в город» описывает очень небольшую часть города. В самосознании большинства жителей Москва городом не является. «Бублик» - это несостоявшаяся провинция.

Как выше уже отмечено, в отличие от периферии, провинция обладает свойствами центральности. Однако в Москве все осложняется ее столичным статусом, из-за которого ее непосредственный центр выполняет надгородские функции.

Чем отличается провинция от центра?

B. Каганский: Центральные функции провинции лежат внутри системы, а [столица] обладает центральными функциями, которые в городе только размещаются. Москва - это вообще центр Северной Евразии, и она собирает население со всей этой территории.

Отсюда вытекает гипотеза, что развитие Москвы как города следует интерпретировать с точки зрения развития идей столичности и государственности. Неслучайно единственный период снижения численности населения Москвы в XX веке приходится на эпоху кризиса государственной власти в начале 1990-х годов.

T. Нефедова: Москва расширяется в среднем каждые 25 лет. Если в городе становится тесно, власти решают раздвинуть границу «на вырост». Как и в советское время, Москва растет примерно на 100000 человек в год. 
Раньше это были не только советские трудовые мигранты (лимитчики), но и учебная, и брачная миграция. В начале 1990-х был короткий период сокращения численности населения Москвы, в том числе за счет оттока лимитчиков, которые столкнулись с ухудшением экономической ситуации и потеряли надежду на получение бесплатного жилья. Это вообще было экономически тяжелое время. Но москвичи почти не уезжали даже тогда. И тем более теперь.

В такой трактовке развитие Москвы происходит под влиянием российского властного ландшафта, который отличается высокой степенью иерархичности и гиперстоличности. Из-за чего наблюдается, в частности, нарушение закона Ципфа: численность населения следующих по величине после Москвы городов должна быть обратно пропорционально их рангу. То есть в СанктПетербурге должно проживать около 6,3, а не 5,3 млн, в Екатеринбурге - 2,1, а не 1,6 млн и т. д.

По поводу перспектив административного роста Москвы эксперты предлагают два сценария, которые условно обозначаются как «пессимистичный» и «реалистичный». «Пессимистичный» заключается в том, что возможный экономический рост рано или поздно вынудит Москву раздвинуть свои границы, тем самым продолжить модель экспансивного роста. «Реалистичный» сценарий исходит из предположения, что уже произошло истощение модели административного роста, из-за чего «реальный город» продолжит расти, но административные границы Москвы больше пересматриваться не будут.

«Пессимистичный» сценарий:

Если подтверждается ваша гипотеза, значит ли это, что мы к 2040-м годам ждем очередное расширение Москвы?

T. Нефедова: Теоретически может быть.

Когда она схлопнется?

T. Нефедова: На самом деле это будет зависеть от того, что будет в стране. Ведь это результат централизации финансов и власти. Если изменится природа управления, то определенно надо ждать изменений и в территориальной структуре.

A. Трейвиш: Если в стране начнется экономический рост, то он не сможет уместиться в рамках Москвы и существующей московской агломерации.

«Реалистичный» сценарий:

О. Вендина: Модель экспансии хороша, когда большие проекты, как в лужковское время, реализуются на новом месте. Это всегда проще, чем заниматься переустройством города. Однако экстраполируя то, что было ранее, в будущее, мы забываем, что жизнь постоянно меняется. Мы, по крайней мере на идейном уровне, уже ушли от модели пространственной экспансии городов. Внутренний город предоставляет много возможностей для развития. Это не значит, что урбанизация остановится, я полагаю, что московская агломерация еще будет расширяться, но административные границы вряд ли будут пересматриваться.

\section{В поисках новой центральности}

Возможные причины того, почему произошел «уход от модели пространственной экспансии городов», кроются в тех проблемах, с которыми пришлось столкнуться после присоединения Новой Москвы в 2012 году. Как можно заметить, в рамках исследования «Археология периферии», представленного в конце 2013 года, рассматриваются территории внутренней периферии в пределах МКАД. Но складывается впечатление, что понимание Москвы, в том числе аспектов центральности и периферизации, становится возможным только в том случае, если мы учитываем прилегающие территории Новой Москвы и Московской области.

В этом случае обнаруживается высокая степень поляризации в распределении функциональной насыщенности между Москвой и ее соседями. При этом Московская область (МО) демонстрирует бо́льшую схожесть с Москвой, чем с соседними областями, тем самым приближаясь по уровню зарплат и качества жизни к столице.

T. Нефедова: В результате поляризация пространства нарастает. Если МО по многим параметрам приближается к уровню Москвы, то разрыв между МО и соседними областями растет. 
Впрочем, и вне МО есть свои полюса роста. Это столицы регионов и их пригороды, хотя и значительно меньшие, чем у Москвы. Это ареалы вдоль основных транспортных магистралей, поскольку вся территории тесно связана со столицей. Так формируется некая структура московского мегалополиса с «дырами» между магистралями и на территориях, удаленных от больших городов. Из таких «дыр» уезжает местное население, но летом они частично заполняются московскими дачниками.

Возможная причина несоответствия между городским содержанием и самоописанием Москвы кроется в отторжении территорий Новой Москвы, которые спустя семь лет после присоединения остаются для города безликой периферией. Однако по поводу субъекта отторжения в этих отношениях есть разные версии. По одной из них, не Москва отторгает территории Новой Москвы, а, наоборот, жители Новой Москвы продолжают считать себя жителями самостоятельных городов и поселений, что иногда приводит к забавным казусам, когда на дорожных указателях «Москва на новых территориях находится, например, в 60 км от... Москвы» [Нефедова, 2018, с. 216].

Стала ли Новая Москва частью Москвы?

B. Каганский: Нет, конечно. Если большая часть Старой Москвы - это не город, то что говорить про Новую Москву? Это такая же периферия.

Почему все еще происходит отторжение территории Новой Москвы?

T. Нефедова: Это не отторжение. Жители Троицка не видят себя москвичами. И местные власти, видимо, не видят себя москвичами. Если вы въезжаете в Новую Москву по Калужскому шоссе, то видите табличку, на которой написано, что люди там живут, как и жили, только пенсии у них стали московскими.

Расширение Москвы в 2012 году связано с идеей того, что московская агломерация и так уже покрывает значительную часть области. Еще до проекта Новой Москвы были планы административно признать сложившиеся размеры агломерации. Тем не менее, по мнению экспертов, реализованный проект по присоединению юго-западного сектора области был необоснованным решением, осуществленным в интересах девелоперов и слабо связанным с задачами агломерационного развития.

А. Новиков: Лужковский проект [расширения Москвы] был другим. Он заключался в объединении Москвы и Московской области и в создании единой агломерации. Тоже не лучшая идея, но это меньшее из двух зол. Присоединение такого спонтанного, ничем не обоснованного «отростка» я не мог предположить даже в страшном сне. Объединение Москвы и Московской области казалось чрезмерным бюрократическим излишеством, координацию работы двух субъектов Федерации в отношении общих проблем Большой Москвы можно было бы решить с помощью различных межведомственных комиссий. <..>

Москву с Московской областью не нужно было объединять. Но в этом хотя бы была логика: тот факт, что московская агломерация накрывает собой большую часть Московской области. Никому в голову не приходило выделять совершенно случайный сектор. Речь шла о живой агломерации и ее административной институализации (что плохо, конечно).

По мнению других экспертов, в этом прослеживается колониальная логика освоения пустого пространства, максимально отвечающая задачам плантационной экономики.

B. Каганский: Если поставить задачу вырезать из Московской области максимально большой кусок, с которым можно делать все, что угодно, в котором нет военно-стратегических объектов, который малозаселен, который к тому же обладает земельными ресурсами для строительства, - этому требованию подобное решение отвечает идеально. Это реализация колониальной логики: где бы нам найти относительно пустое пространство, которое мы можем переработать под жилую застройку. 
Однако Новая Москва сыграла нетривиальную роль в истории развития Москвы в целом. По одной из версий, именно благодаря конкурсу проектов по развитию Новой Москвы профессиональное сообщество смогло обратить внимание московского правительства на важность развития внутренних территорий. Сама по себе Новая Москва продолжила развиваться по инертному сценарию застройки, характерному для прилегающих территорий Московской области. Однако именно с тех пор обозначился кризис модели экспансивного роста, а приоритеты развития Москвы сместились в пользу актуализации ценности общественных пространств $^{2}$.

О. Вендина: Конкурс на проект развития Большой Москвы, который был парафразом конкурса на проект Большого Парижа, сделал большой прорыв в развитии градостроительных идей. Конкурс задумывался как престижная акция, он ставил амбициозную цель: развитие Москвы как глобального города с использованием наиболее современных концепций и достижений. В конкурсе приняли участие многие мировые и российские архитектурные звезды. Все иностранные участники в один голос говорили о ценности городских общественных пространств и необходимости формирования среды жизни человека, а также второстепенности коммерческих задач. <...>

Они сказали, что Большая Москва - это не лучшее решение. Они также отметили, что Москва и без расширения территории обладает огромным количеством территориальных ресурсов, что город нужно перестраивать и реконструировать, а не только «растягивать» в разные стороны. Многие специалисты попытались осмыслить, какую функциональную и социальную пользу для Москвы можно извлечь из волюнтаристского политического решения.

A. Острогорский: Идея о периферии казалась правильным и гуманистическим ходом. Если помните, сборник «Археология периферии» открывается текстом о культе центра. Со стороны правительства Москвы это совпадало со многими актуальными повестками. Одна из очень важных вещей: это все происходило в продолжающемся шоке от проекта «Новая Москва»проекта, который проблематизировал центробежное движение. «Археология периферии» является ответом на эту проблему. На необходимость обратить внимание на эту территорию.

Новая Москва обратила внимание на Старую Москву - вы согласны с этим тезисом?

A. Острогорский: Да. Как минимум большинство участников конкурса заняли однозначную позицию, что они очень скептически относятся к новой территории, что обсуждать отдельные части агломерации - это странная затея, это большой город, у него есть разные части, есть центр. Это заставило многих задуматься над тем, что происходит с центром и с разными слоями, что там находится. <...>

Мне неизвестно, как был сформулирован заказ на это исследование. Но по последующим крупным проектам мы видим, что они каким-то образом к этому адресуются. МЦК и общее развитие транспортного каркаса. Даже реновация, не даже, а в первую очередь. Описание одного из вызовов реновации как выравнивание плотности между центром и дальней периферией - это описание содержится в описании двух центров - центра и МКАД - в сборнике.

Следующая, не менее масштабная, проблема, с которой еще предстоит столкнуться Москве, это проект реновации. Смещение интереса властей в пользу развития внутренних территорий можно трактовать по-разному. По мнению одних экспертов, проект реновации является прямым продолжением колониальной логики развития города, который за счет тех же механизмов переделывает периферийные территории, но уже не пустые, как это было с Новой Москвой, а наполненные. Причем проект реновации вступает в конфликт с существующими про-

2 Здесь уместно привести замечание рецензента, который указывает на то, что в связи с присоединением новых территорий в 2017 году был утвержден проект внесения изменений в Генплан Москвы, который направлен на «развитие полицентрической структуры города и его столичных функций». С документами можно ознакомиться по ссылке: https://www.mos.ru/mka/documents/normativnye-pravovye-akty-g-moskvy/ view/144646220. 
ектами территориального развития на территории Новой Москвы, переключая строительные мощности на себя.

B. Каганский: Реновация стала альтернативой Новой Москве. Нужно заработать на постройке $\mathrm{N}$ млн кв. метров для размещения М количества людей. Один проект был внутренний, разместить за счет уплотнения, а другой внешний - за счет новых территорий. Поэтому застройка Новой Москвы при запуске программы реновации идет сейчас не очень активно. Совместное наступление этих проектов - это противоречия авторитарной власти, которой все сложнее согласовывать разные интересы. Это конкурирующие проекты. <..>

Реновация является типичной колониальной политикой, которую центр проводит по отношению к периферии, тем самым решая свои собственные задачи. Одна из этих задач загрузка мощностей гиперцентрализованного строительного комплекса. <...>

Надо заметить, что реновация стала возможной только в условиях высокой степени централизации и Москвы, и государства. Если централизация остановится, то не будет такого спроса на московское жилье. Проблемы внутренней периферии - «бублика» - производны от проблем Российского государства.

По мнению других экспертов, проект реновации не является следствием Новой Москвы. За каждым проектом скрываются разные группы интересов и разные концепции. Однако в случае с реновацией произошло совпадение коммерческого интереса и социальной логики развития города.

О. Вендина: Городское пространство является одновременно категорией стоимости и общественного блага. Мне кажется, что за последние пять-шесть лет, после конкурса на проект развития Большой Москвы, мысль о городе как общем достоянии вошла в сознание чиновников и людей. Проект реновации, пожалуй, один из проектов, которые сочетают в себе эти две функции. И здесь явно происходит конкуренция коммерческого и социального подходов. <...>

Можно ли сказать, что проект реновации - это следующий этап, необходимость которого обозначилась после того, как проект Новой Москвы себя исчерпал?

О. Вендина: Нет. Стадиальный подход для рассмотрения московских проектов не годится. Одно себя исчерпало, поэтому беремся за другое. Такой последовательности нет. Это разные группы интересов и разные проекты, которые следуют разным концепциям. Дело не в том, что Новая Москва себя исчерпала, она еще долго себя не исчерпает, а в том, что есть реальные проблемы с пятиэтажным жилым фондом.

Другая позиция заключается в том, что, признавая девелоперскую модель развития Москвы и проблемы плантационной экономики, нам все же стоит обратить внимание на то, что на данный момент застройщикам все труднее игнорировать качество городской среды. Принцип "location location location" перестает играть исключительную роль в вопросе ценообразования на рынке недвижимости. К тому же объявление о начале реновации как перформативное высказывание не только снизило цены на жилье в определенных районах Москвы, но и передвинуло интересы застройщиков в Подмосковье. Тем самым мы можем наблюдать картину грандиозного передела сложившихся поясов застройки, некоторые из которых могут быть «затронуты» спустя десятилетия.

А. Новиков: Недавно произошла масштабная интервенция в рынок строительства Москвы, она пока что больше словесная, но все же мощная - это программа реновации. Программа затрагивает $10 \%$ населения, $15 \%$ территории, правда, сейчас ее параметры становятся скромнее: раньше начинали с 15 000, а сейчас около 7000 домов. <...>

Тем не менее эта словесная интервенция и начало работ по вводу новых объемов жилья привели к падению цен на рынке жилья. В рабочих группах настойчиво предупреждали: «Вы не знаете, как поведет себя цена на квадратный метр». Казалось неизбежным, что при таком предложении нового жилья спрос должен среагировать однозначно - стоимость ме- 
тра должна упасть. Что и произошло. Причем неодинаково во всей Москве, а в поясе, где стали появляться новые форматы предлагаемого жилья. Стоимость квартир, например, у метро «Университет» в долларовом измерении упала более чем в 1,5 раза за два года. Тут и девальвация валюты, конечно, помогла, но не только она. <...>

Этот процесс покончил с устойчивостью московского рынка жилья. Инвесторы потеряли часть своего капитала. Притом что в Московской области, по данным Института экономики города, была обратная ценовая динамика. Вся плантационная экономика ушла в сторону области. Жилье там дешевое, появляются новые стандарты, оно там растет, а Москва теперь слишком непредсказуема. Следующим, видимо, будет спальный пояс Москвы, где типаж домов однообразный и все менее соответствует нормам и запросам среднего класса. Сюда, возможно, придет следующая волна падения цен. Сейчас удар принял срединный пояс Москвы. <...>

Следующим объектом реновации, скорее всего, будут новостройки за МКАД. И об этом нужно думать. Подмосковные компактные города могут стать реальной альтернативой московским микрорайонам. И тогда микрорайоны начнут проваливаться по цене и по престижу - и с ними надо будет что-то делать.

Обозначенная перспектива переустройства города поднимает вопросы о перераспределении баланса между центром и периферией. Напомним, что по этому поводу в «Археологии периферии» вводилось противопоставление двух концепций: расширения центральности и полицентричности [Вендина, Муратов, 2013, с. 432-433]. Первая из них предложена итальянскими урбанистами Бернардо Секки и Паола Вигано и исходит из необходимости поддержания социальной и физической непрерывности города. В контексте развития московской агломерации эксперты обращают внимание на непропорционально маленький центр Москвы по отношению ко всему городу. Размер центра, который в такой интерпретации в лучшем случае ограничен Третьим транспортным кольцом (ТТК), является не центром обычного города, а всего лишь столичной резиденцией, а потому не нуждается в решении вопросов территориального развития по отношению к периферии.

Правильно ли я понимаю, что Москву сложно воспринимать как город и что она ведет себя больше не как центр, а как столица или как государство?

B. Каганский: Как имперская резиденция, расплывшаяся в огромной городской агломерации. Пятно застройки давно вышло за МКАД. При этом для 20-миллионной Москвы поразительно маленький центр. Получается, что у города с таким населением должен быть огромный центр, который бы вышел за пределы ТТК, - и тогда неизбежно «бублик» бы становился провинцией, а центральные функции были бы распределены.

Необходимости расширения центральности противопоставлен подход, направленный на развитие полицентричности - появления функциональных узлов притяжения (центров второго порядка) на территории периферии.

О. Вендина: Полицентричность подразумевает преодоление недостатков периферийного положения, прежде всего функциональной бедности жизни спальных окраин за счет целенаправленного развития и поддержания центров второго порядка, где концентрировались бы значимые торговые, транспортные и культурные объекты. Такие центры второго порядка могли бы замыкать многие жизненные потребности людей на себя, освобождая их от необходимости ехать в центр города, теряя при этом массу времени и сил. А концепция расширяющейся центральности - про то, что периферийности в принципе не должно быть в городском пространстве, потому что оно чрезвычайно ценное и тесное. Понятие центральности должно быть более дифференцированным, учитывать не только разнообразие функций, но и разнообразие социальных позиций. Центральность должна быть распределенной, позволяя избежать «вымороченных» периферийных зон. Периферии в привычном смысле слова в данной концепции не существует, поскольку то, что является периферийным с точки зрения одних видов деятельности, может быть центральным с точки зрения других. Расширяется понятие центральности - расширяется и его пространственное воплощение. 
Однако и та и другая концепции сталкиваются с реальностью. Принципиального расширения центральности не происходит: центр Москвы остается все так же ограничен, качество жизни внутри центра и за его пределами продолжает сильно отличаться, что символически отражается в престижности и стоимости недвижимости. С другой стороны, системные попытки создать очаги центральности за пределами центра сталкиваются с тем, что фрагментарная функциональная насыщенность не позволяет сделать качественный скачок (как это, например, происходит с окраинными городами) и кардинально изменить качество жизни на периферии. В связи с этим возникает ощущение, что реновация является тупиковым инструментом, который реализуется в рамках уже привычных сценариев развития Москвы и не способен предложить новых идей для переустройства города.

A. Острогорский: Если реновация - это системный ответ, то возникает вопрос: должна ли Москва так развиваться? Потом мы снесем все следующие серии домов? И так мы будем волнами все перестраивать? Я думаю, что опыт реновации скоро покажет, что это нереализуемо. Идея суперпарка, которая предлагала по-новому трактовать пространство, а не отрицать его, увидеть новые качества - эта идея не прошла, потому что она не получает экономической поддержки, связанной со стройкой.

Возможно, решение проблемы нужно искать в «расширении» центральности, но понимая под этим не территориальную экспансию центра, а переосмысление того, что вообще считать центром, какими свойствами и качествами он должен обладать.

О. Вендина: Возможно, со временем можно будет говорить и о расширяющейся центральности. Однако подчеркну: реализация данной концепции не предполагает, что Москва от Кремля «до самых до окраин» будет однородной средой «как в центре». Напротив, данная концепция предполагает поддержку разнообразия и развитие контактности городской среды, что и позволяет центральности расширяться за счет социальных и пространственных связей.

Отчасти проявления такого концептуального смещения мы можем наблюдать в рекламных манипуляциях застройщиков, предлагающих недвижимость на окраинах, которая, по их заверениям, будет не просто соответствовать жизни «как в центре», а будет якобы самим центром. Отсюда слоганы: «Центр - там, где я», «Мой центр мира» и «Мой район - мой центр»3.

В результате эксперты сталкиваются с необходимостью поиска новых ценностей, без которых невозможно переосмысление отношений между центром и периферией. Взятый в рамках программы «Мой район» курс на развитие полицентричности не предлагает радикально новых ценностей для жизни за пределами центра. Неслучайно в своем выступлении на МУФ2019 Г. Ревзин предлагает уйти от концепции полицентричности в пользу развития периферийных территорий как отдельно взятых городов.

Г. Ревзин: Когда говорят, что «Мой район» является продолжением программы «Моя улица», то это в смысле хозяйственно-строительной деятельности, но концептуально это жуткая проблема. <...>

Пять лет назад мы считали, что там нужно делать что-то морфологически похожее на центр. Сегодня я так не считаю. Я не считаю, что спальные районы можно делать так же, как и центры. Мы должны делать что-то другое. <...>

Сейчас я исхожу из того, что каждый район нужно решать как город. Наши районы в Москве - это поселения с населением около 100000 человек. Это вообще-то малый город. И когда мы говорим про мастер-план районов, то мы должны понимать, что идеология этого мастер-плана должна быть сделана так, как будто это отдельный город - то есть у него свой центр, своя центральная улица, своя объездная зона, своя периферия, свое зонирование.

3 Слоганы застройщика «Инград»: http://img.advertology.ru/aimages/2019/06/10/ingrad_1.jpg; https://www. sostav.ru/images/news/2019/03/29/slides/zu78nnYJ_m.jpg; https://www.sostav.ru/images/news/2018/05/17/ s71psana.jpg. 
Эти мастер-планы должны быть основаны на других ценностях, чем ценности в центре. Мы не можем дотянуть жизнь в спальных районах по качеству до уровня центра. Мы можем создать альтернативу центру, где есть свои ценности, не похожие на те, что в центре.

Принципиально иное направление поиска альтернативных ценностей жизни за пределами центра предлагает А. Новиков. Его идея отталкивается от концепции аэротрополиса Дж. Казарды [Kasarda, 2001] и предлагает смотреть на периферию Москвы и ближайших областных центров как на пригороды, но не Москвы, а московских аэропортов. По мнению А. Новикова, противопоставление этих территорий центру обрекает их на невыгодные сравнения, а переориентация на принципиально иные преимущества, например, на близость к аэропортам, позволяет периферии найти собственные аспекты центральности.

А. Новиков: У меня есть представление о том, что малые и средние города (Кашира, Тула, Серпухов, Зарайск, Клин) - это города, которые в скором будущем окажутся более привлекательными для москвичей, чем [внутренние] микрорайоны. Это шикарные места с фантастическими ландшафтами вокруг, с удобной исторической планировкой и старой жилой застройкой с разнообразной квартирографией, а также с высокой доступностью аэропортов. А пока логика у местных властей в этих городах, как правило, такова: мы не Москва, мы сами по себе. Но эта логика противостояния затягивает, и эти города начинают проигрывать Москве, становясь сателлитами, вместо того чтобы стать настоящей Москвой, с центральным качеством городской среды.

\section{Старые и новые инфраструктуры}

На примере близости к аэропорту мы можем заметить, каким потенциалом обладает транспортная инфраструктура в плане перераспределения баланса между центром и периферией. В данном контексте представляется важным обсудить, какое функциональное наполнение привносят и привнесут имеющиеся (МКАД, МЦК) и строящиеся (МЦД) системы.

Если говорить о МКАД, то сразу же возникает противопоставление ее барьерных и контактных функций. С одной стороны, МКАД продолжает оставаться физическим барьером, пересечение которого возможно лишь в определенных точках доступа, что сильно ограничивает потоки в Москву извне. С другой стороны, МКАД превратилась в полноценную торговую артерию, которая привлекает потоки посетителей как из области, так и из города.

А. Трейвиш: МКАД мешает физически, как стена. Въехать и съехать трудно. Пересечь этот барьер можно только по вылетным магистралям. Вдоль МКАД с обеих сторон жилые районы, но связи между ними нет. С тех пор как Москва выплеснулась за МКАД, эта дорога все равно превратилась во внутригородское или внутриагломерационное кольцо. Сейчас это фактически торговая улица. Не как Тверская, а как улица для автомобилистов.

О. Вендина: Чтобы убедиться в сказанном, достаточно проехаться по МКАД. Эта трасса, призванная разгрузить транспортные потоки Москвы, превратилась в главную торговую и деловую «улицу» Московской области, ее центр. Характерно, что внешняя сторона МКАД довольно плотно застроена, а внутренняя - не очень, здесь много зелени, из-за которой в отдалении выглядывают крыши домов. Территории, отвечающие представлению о городе и создающие его образ, оказались снаружи, а о пригороде - внутри. Вот такая инверсия.

Другой не менее важный вопрос заключается в том, продолжает ли МКАД оставаться физической или символической границей Москвы. Если раньше символический каркас города однозначно сложно было представить без МКАД [Глазков, Гнилорыбов, 2017], которая являлась дополнительной шкалой удаленности от центра, то сейчас после существенной территориальной экспансии Москвы в область МКАД все больше обретает свойства центральности.

В. Каганский: МКАД становится новым утилитарным центром, не символическим. Функцию границ она продолжает выполнять в транспортном отношении, так как не везде ее можно пересечь. 
Признавая за МКАД некоторые аспекты центральности, эксперты тем не менее считают, что в дальнейшем потребуется существенная реконструкция кольцевой дороги, которая бы повысила связанность урбанизированных территорий по обеим ее сторонам.

\section{Продолжает ли МКАД быть границей?}

A. Острогорский: Нет, конечно. Она все больше становится проблемой непереходимого барьера. Понятно, что плотность вдоль МКАД будет повышаться. Значит, вокруг всех этих развязок возникнет город. С ростом города его придется убирать, сносить, переделывать, как неправильно вросшую кость. Был такой проект на «Стрелке»: «МКАД как бульвар» можно себе такое представить.

С другой стороны, благодаря своим барьерным функциям МКАД продолжает технически и символически ограничивать Москву, вынуждая администрацию города обращать внимание на потенциал развития внутренних территорий.

А. Новиков: Понятно, что идет застройка МКАД с обеих сторон. Со стороны Московской области - моллы. Это точно нельзя назвать центром, потому что это среда абсолютно не городская, а, скорее, логистическая. Внутри молл, может быть, и представляет собой мини-город, но не более того. Это контрсреда. Это барьер, через который очень мало пешеходных смычек. <...>

Он остается крепостью. Количества низовых смычек там очень не хватает. Отчасти это и хорошо, и плохо. Плохо - понятно почему. Хорошо - потому что МКАД символически выполняет роль зеленого пояса вокруг Лондона как ограничителя расползания. У вас полно внутри Москвы места, давайте реорганизуем пространство, нечего выходить за пределы Москвы.

Другое транспортное кольцо - МЦК - интересно тем, что после своего запуска в 2016 году стало наиболее значимым инфраструктурным объектом, полностью расположенным за ТТК. Обсуждая, удалось ли МЦК создать новые точки притяжения, эксперты сходятся во мнении, что пока его станции не стали полноценными субцентрами. Этому мешает в том числе сильная конкуренция со стороны центра и МКАД, однако в конце концов высокий пересадочный потенциал и новый пассажирский поток поднимут уровень функционального наполнения МЦК.

В «Археологии периферии» делался прогноз, что МКЖД (прежнее название МЦК) и МКАД будут новыми точками притяжения, - прогноз сбылся?

О. Вендина: Любая инфраструктура, и особенно пересадочная, выполняет узловые функции, а значит, является фокусом притяжения различных видов деятельности. И если прогноз, данный в «Археологии периферии», еще не сбылся, то он сбудется. Нужно время. Территория, по которой проходит МЦК, находится в зоне двойной периферии. Она испытывает сильную конкуренцию как со стороны линейного центра, которым является МКАД, так и центра Москвы. Процесс формирования точек притяжения небыстрый. Помимо пересадочного узла и обычных сопутствующих ему торговых киосков, в таких местах должно появиться еще что-то, повышающее символическую ценность места.

Получается ли у МЦК уже сейчас привносить центральность?

А. Новиков: О да! Наполняемость МЦК прекрасна. Кольцо сгенерировало новый поток даже в большей степени, чем помогло разгрузить радиальные линии. Это означает, что раньше жители спальной периферии отказывали себе в поездке, и такие маршруты даже в голове не держали, а сейчас доступность резко выросла. И это замечательно для города. Потому что чем больше трафик, тем лучше работает пересадочный узел и тем сильнее он притягивает потребительский спрос и функционирует как центр экономической активности. Правда, это процесс не быстрый, но иначе и быть не может.

Судя по названию, Московские центральные диаметры (МЦД) вслед за МЦК тоже претендуют на привнесение свойств центральности на территории, по которым будут проложены 
маршруты. Однако данный инфраструктурный объект интерес тем, что он в явном виде покидает пределы Москвы. Отсюда вопрос: кто же будет основным бенефициаром от его ввода и эксплуатации, Москва или Московская область?

По мнению экспертов, МЦД - агломерационный проект. С одной стороны, он должен помочь разгрузить локальную транспортную инфраструктуру. С другой стороны, сам факт реализации этого проекта показывает, что в сложившемся конфликте интересов между Москвой и Московской областью МЦД отвечает на общий запрос о росте функциональной связанности в пределах реальной агломерации.

О. Вендина: В данном случае речь идет не о «реальных размерах», а о функциональном единстве агломерации, в которой функционируют не только иерархические связи, направленные в центр и из центра, но и горизонтальные - между разными точками, прилегающего к агломерационному ядру пространства. Иногда это ядро является лишь зоной транзита.

К тому же заявленная тенденция на поиск функционального наполнения за пределами Москвы может позволить внутренней периферии изменить свою ориентацию в пользу других центров, например, тех же аэропортов.

Е. Летуновская: Мы затрагивали эту тему в одном из конкурсов по реновации, еще до ярких публичных анонсов МЦД. Район, которым мы занимались, был бусинкой на этой устаревшей железной дороге. И если бы это была удобная скоростная дорога, то этот район начал бы работать вовне больше, чем внутрь Москвы. Обычный спальный район [Головинский], скорее, превращается в самодостаточный пригород, но не Москвы, а в нашем случае - Шереметьево, за счет этой ж/д связи. О проекте МЦД мы еще не знали. Мы ссылались на опыт Большого Парижа.

Так или иначе, развитие транспортной инфраструктуры, а также ее взаимное пересечение с остальными дорогами и рекой создает, по мнению экспертов, неплохой потенциал для возникновения настоящих субцентров.

А. Новиков: МЦК и Третье кольцо обсуждались еще во времена Лужкова. Однако жизнь инфраструктурных проектов длиннее, чем политическая жизнь мэров. Оно было задумано еще тогда, и это один из лучших современных проектов Москвы. У Москвы есть замечательный инфраструктурный каркас, который позволяет получить зрелые центры на пересечениях МЦК, ТТК и Москвы-реки. Получается как минимум четыре отличных перехватывающих центра. Это отражено и в Генплане. Вопрос лишь в том, сколько понадобится времени и усилий для того, чтобы эти пересечения стали реальными субцентрами Москвы.

\section{Вместо заключения. Археология периферии 2.0}

Обсуждая необходимость проведения повторного исследования по следам «Археологии периферии», эксперты не приходят к единому мнению. В основном расхождения возникают по поводу выбора исследовательской оптики, а именно в понимании периферии.

Одни продолжают считать, что территория между ТТК и МКАД (внутренняя периферия) все так же остается наиболее непонятной и неизведанной территорией.

B. Каганский: Нужны полевые исследования, пешие маршруты, с аудио- и видеосъемкой. Чтобы откартировать внутреннюю периферию Москвы, чтобы понять, какие типы зон там есть. Чтобы понять морфологию этого пространства. Нащупать очаги новой центральности. Пока что она остается недостаточно изученной.

Другие эксперты придерживаются мнения, что повторение исследования в границах той же территории носило бы исключительно мониторинговый характер. При этом как тогда, так и сейчас выделение этой территории само по себе не позволяет наделить ее особым онтологическим статусом. 
А предметным фокусом «Археологии периферии 2.0» был бы тот же «бублик»?

A. Острогорский: Не думаю. Разве что если в риторическом смысле, в качестве какого-то регулярного мониторинга - наверное, это было бы интересно читать. Но повторюсь, что тогда выделение периферии было чисто аналитическим ходом. Это не связано с реальностью. Ее как таковой не существует.

Третьи эксперты расценивают возможность проведения повторного исследования как способ сместить фокус на изучение отношений между Москвой, Московской областью и прилегающими регионами. Причем принципиальное значение имело бы изучение собственно фронтира - неуловимого перехода между московским мегалополисом и другими субъектами.

T. Нефедова: Для меня было бы важно поговорить о том, как изменились различия между Москвой, Московской областью, соседними и более удаленными регионами. Как эта «ступенчатость» определяет поляризацию нашего пространства и что будет на каждом из этих уровней. Даже больше всего интересовал бы переход от Московской области к окружающим ее регионам, ведь это очень «болезненная часть» России.

Однако увеличение масштаба не означает снижения интереса к внутренней периферии. Наоборот, когда деление на внутреннее и внешнее приобретает высокую степень условности, становится более очевидным, что изменения любой части агломерации приводят к новому перераспределению баланса между центром и периферией, а значит, интерес к территориям за административными пределами Москвы позволит лучше понять специфику процессов внутренней периферии.

А. Новиков: Московская спальная периферия - фантастически интересный объект, нигде в мире такого не сыщешь. Огромный город, который, если сделать правильно, получит колоссальный рост качества жизни и экономической выгоды.

В связи с проектами реновации возникла совсем другая ситуация. Ее необходимо осмыслить уже не только в границах «бублика», а в пределах всей агломерации. Я не имею в виду только Новую Москву, а говорю о всей живой агломерации. Раньше пробки были в центре города, потом перешли в «бублик». А сейчас «пробки» сместились в Московскую область. Москва даже по этому параметру - по повседневным проблемам передвижения - уходит туда, в область. Появляются новые модели жизни, связанные с аэропортами. Аналитически надо точно выходить за пределы не только области, а дотягиваться до центров ближайших областей (Владимир, Рязань, Тула, Калуга, Смоленск, Тверь, Ярославль). <...>

Некоторые эксперты при этом считают, что академически и интеллектуально идеи «Археологии периферии» остаются все еще неосвоенными. Заложенные в сборник соображения требуют дополнительного раскрытия и могут послужить вектором для новых исследований исследований.

О. Вендина: Я думаю, что такие знаковые исследования, которые отражают поворот урбанистической мысли, должны случаться не чаще одного раза в 10 лет. Мне кажется, что те мысли, которые тогда были сформулированы, еще и сейчас не до конца освоены, а сформулированные там тезисы не отвергнуты и не нуждаются в пересмотре. Мне кажется, что более правильный путь - реализация проектов, которые бы проверяли сформулированные в «Археологии периферии» новые идеи, не получившие достаточного обоснования.

Таким образом, московская периферия все еще остается малоизученной. Попытки ее административного, аналитического, поточного и онтологического выделения сталкиваются с проблемой концептуальных противоречий между разными подходами по поводу того, что считать центром, периферией, периферизацией, центральностью, полицентричностью, агломерацией и т.д. На данном этапе нам удалось лишь кратко обозначить основные точки соприкосновения различных взглядов на данные вопросы. Одно не вызывает сомнений: бурно меняющаяся Москва еще не раз предложит вопросы для теоретических дискуссий и эмпирических исследований. 


\section{Источники}

Археология периферии (2013) Сборник статей. М.: Strelka Institute.

Вендина О., Муратов А. (2013) На пути к суперпарку//Археология периферии. Сборник статей. M.: Strelka Institute. C. 432-453.

Глазков К., Гнилорыбов П. (2017) «Кочующая» топонимика: транспортная система как движущая сила названий в Москве//Неприкосновенный запас. Т. 2. № 112. С. 232-252.

Голубчиков О.Ю., Махрова А.Г. (2010) Современные процессы урбанизации в Подмосковье: феномен «окраинного города»//ACADEMIA. Архитектура и строительство. Т. 4. С. 63-68.

Гутнов А.Э. (1984) Эволюция градостроительства. М.: Стройиздат.

Каганский В.Л. (1998) Центр - провинция - периферия - граница. Основные зоны культурного ландшафта//Культурный ландшафт: вопросы теории и методологии исследований: семинар «Культурный ландшафт. С. $72-101$.

Каганский В.Л. (2015) Ситуация границы и логико-семиотические типы границ//Международный журнал исследований культуры. Т. 4. № 21. С. 5-27.

Махрова А., Нефедова Т., Трейвиш А. (2012). Москва: мегаполис? агломерация? мегалополис? //Демоскоп Weekly. № 517-518. С. $1-26$.

Махрова А.Г., Кириллов П.Л. (2016) Маятниковые трудовые миграции как образ жизни в агломерациях. Пример Московской области //Между домом и... домом. Возвратная пространственная мобильность населения России /Т.Г. Нефедова, К.В. Аверкиева,А.Г. Махрова (ред.). М.: Новый хронограф.

Нефедова Т. (2018) Новая Москва за пределами ее городов//Старая и Новая Москва: тенденции и проблемы развития. М.: Изд. ИП Матушкина И.И.

Новиков А., Котов Е., Гончаров Р., Никогосян К., Городничев А. (2016) Москва: курс на полицентричность. Оценка эффектов градостроительных проектов на полицентрическое развитие Москвы. М.: Высшая школа урбанистики.

Россман В. (2013) Столицы. Их многообразие, закономерности развития и перемещения. Издательство Института Гайдара.

Blowers A., Leroy P. (1994) Power, Politics and Environmental Inequality: A Theoretical and Empirical Analysis of the Process Of 'Peripheralisation'//Environmental Politics. Vol. 3. No. 2. P. 197-228.

Danson M., De Souza P. (eds.) (2012) Regional Development in Northern Europe. Peripherality, Marginality and Border Issues. London: Routledge.

Daum A. (2000) America's Berlin 1945-2000: Between Myths and Visions//Berlin: The New Capital in the East. A Transatlantic Appraisal/F. Trommler (ed.). Washington, D.C: American Institute for Contemporary German Studies, The Johns Hopkins University. P. 49-73.

Fujita M., Ogawa H. (1982) Multiple Equilibria and Structural Transition of Non-Monocentric Urban Configurations//Regional Science and Urban Economics. Vol. 12. No. 2. P. 161-196.

Garreau J. (1991) Edge City: Life on the New Frontier//American Demographics. Vol. 13. No. 9. P. 24-31.

Herrschel T. (2011) Regional Development, Peripheralisation and Marginalisation-And The Role of Governance //The Role of Regions? Networks, Scale, Territory/T. Herrschel, P. Tallberg (eds.). Kristianstad: Kristianstad Boktryckeri. P. $85-102$

Jonas A. E. (2003) Making Edge City: Post-Suburban Development and Life on the Frontier in Southern California//Changing Suburbs: Foundation, Form and Function/R. Harris, P. J. Larkham (eds.). London, New York: Routledge. P. 202-221.

Kasarda J. (2001) From Airport City to Aerotropolis. Airport World. No. 6. P. 42-47.

Lang T. (2012) Shrinkage, Metropolization and Peripheralization in East Germany//European Planning Studies. Vol. 20. No. 10. P. 1747-1754.

Teaford J.C. (1997) Post-Suburbia: Government and Politics In the Edge Cities. Baltimore, MD: Johns Hopkins University Press. 


\section{KONSTANTIN GLAZKOV \\ THE ARCHEOLOGY OF THE PERIPHERY: SIX YEARS LATER}

Konstantin P. Glazkov ${ }^{1}$ PhD in Sociology, Lecturer at the Sociological Department, HSE University; 20 Myasnitskaya Street, Moscow, 101000, Russian Federation, tel.: +7 9778455251

E-mail: glazkov.konst@gmail.com

\section{Abstract}

In December 2013, comprehensive research on the outskirts of Moscow was presented at the Moscow Urban Forum (MUF) The archeology of the periphery. It included six areas: society, politics, architecture, culture, economics, and data. Research teams noted the significant potential of the peripheral parts of the city, which are still in mode of "dormitory" centers. Nevertheless, these territories still remained only urban parts, not city-forming. One of the criticisms of this project was the insufficient disclosure of the relationship between the center and the periphery, which could shed light on the reasons for the poor realization of the potential of the peripheral territories.

Six years have passed. Moscow is booming. For three years now, the Moscow Central Circle (MCC), which lies on the territory of the periphery, has been functioning. The introduction of a new large-scale transport infrastructure - the Moscow Central Diameters (MCD) - which will spread outside Moscow has been announced. The city is experiencing the opening of new metro lines, several improvement projects ("My Street", "My District”) and an active phase of housing renovation. It makes sense to recall the old results and conclusions in order to evaluate the development that has formed since the publication of "The Archeology of the Periphery". To do this, we talked with the authors to comprehend the changes taking place in Moscow, which is trying to find a balance between the center and the periphery.

Eight interviews with the experts who were responsible for various research areas were analyzed. We discussed where Moscow ends, what can be called the periphery of Moscow, whether we should wait for the next administrative expansion of the city, how the accession of New Moscow affected the development of the whole city, whether the "My District" project will be able to form a polycentric urban environment, what the prospects of the Moscow housing renovation are, what role the MKAD plays in modern Moscow, how the three-years of the MCC operation has affected the peripheral territories, what to expect from the launch of the MDC, and what "The Archeology of the Periphery 2.0" could be about.

Key words: center; periphery; peripheralization; agglomeration; Moscow; MKAD; MCC; MCD

Citation: Glazkov K.P. (2019) Archeology of the Periphery: Six Years Later. Urban Studies and Practices, vol. 4, no 2, pp. 86-103 (in Russian). DOI: https://doi.org/10.17323/usp42201986-103

\section{References}

Arheologija periferii [Archeology of the periphery] (2013) Sbornik statej [Digest of articles], M.: Strelka Institute. (in Russian)

Blowers A., Leroy P. (1994) Power, Politics and Environmental Inequality: A Theoretical and Empirical Analysis of the Process of 'Peripheralisation'. Environmental Politics, vol. 3, no 2, pp. 197-228.

Danson M., De Souza P. (eds.) (2012) Regional Development in Northern Europe. Peripherality, Marginality and Border Issues. London: Routledge, pp. 49-64.

Daum A. (2000) America's Berlin 1945-2000: Between myths and visions. Berlin: The New Capital in the East. A Transatlantic Appraisal, pp. 49-73.

Fujita M., Ogawa H. (1982) Multiple equilibria and structural transition of non-monocentric urban configurations. Regional science and urban economics, vol. 12, no 2, pp. 161-196.

Garreau J. (1991) Edge city: Life on the new frontier. American Demographics, vol. 13, no 9, pp. 24-31.

1 Research interests: microsociology, public behavior, location-based services. 
Glazkov K., Gnilorybov P. (2017) «Kochujushhaja» toponimika: transportnaja sistema kak dvizhushhaja sila nazvanij v Moskve ["Nomadic" toponomy: transport system as a driving force for names in Moscow]. Neprikosnovennyj zapas [Untouchable reserve], vol. 2, no 112, pp. 232-252. (in Russian)

Golubchikov O.Ju., Mahrova A.G. (2010) Sovremennye processy urbanizacii v Podmoskov'e: fenomen «okrainnogo goroda» [Modern processes of urbanization in the suburbs: the phenomenon of the "edge city"]. ACADEMIA. Arhitektura i stroitel'stvo [Architecture and construction], vol. 4, pp. 63-68. (in Russian)

Gutnov A.E. (1984) Evolyuciya gradostroitel'stva. [The Evolution of Urban Planning]. M.: Strojizdat. (in Russian)

Herrschel T. (2011) Regional development, peripheralisation and marginalisation-and the role of governance. The Role of Regions? Networks, Scale, Territory/T. Herrschel, P. Tallberg (eds.). Kristianstad: Kristianstad Boktryckeri, pp. 85-102.

Jonas A. E. (2003) Making edge city: Post-suburban development and life on the frontier in southern California. Changing Suburbs: Foundation, Form and Function/R. Harris, PJ, Larkham (eds.). London, New York: Routledge, pp. $202-221$.

Kaganskij V.L. (1998) Centr-provincija-periferija-granica. Osnovnye zony kul'turnogo landshafta [Center-province-periphery-border. The main areas of the cultural landscape]. Kul'turnyj landshaft: voprosy teorii $i$ metodologii issledovanij: seminar «Kul'turnyj landshaft [Cultural landscape: issues of theory and research methodology: seminar “Cultural landscape], pp. 72-101. (in Russian)

Kaganskij V.L. (2015) Situacija granicy i logiko-semioticheskie tipy granic [The situation of borders and logical-semiotic types of borders]. Mezhdunarodnyj zhurnal issledovanij kul'tury [International Journal of Cultural Studies], vol. 4, no 21, pp. 5-27. (in Russian)

Kasarda J. (2001) From airport city to aerotropolis. Airport world, no 6, pp. 42-47.

Lang T. (2012) Shrinkage, Metropolization and Peripheralization in East Germany. European Planning Studies, vol. 20, no 10, pp. 1747-1754.

Mahrova A., Nefedova T., Trejvish A. (2012) Moskva: megapolis? aglomeracija? megalopolis? [Moscow: a megalopolis? agglomeration? megalopolis?]. Demoskop Weekly, no 517-518. pp.1-26. (in Russian)

Mahrova A.G., Kirillov P.L. (2016) Majatnikovye trudovye migracii kak obraz zhizni v aglomeracijah. Primer Moskovskoj oblasti [Pendulum labor migrations as a way of life in agglomerations. An example of the Moscow region]/Mezhdu Domom I... Domom. Vozvratnaja Prostranstvennaja Mobil'nost' Naselenija Rossii. [Between House And ... House. Return Spatial Mobility of the Population of Russia]. M: Novyj Hronograf [New chronograph]. (in Russian)

Nefedova T.G. (2018) Novaja Moskva za predelami ee gorodov [New Moscow outside its cities]. Staraja i Novaja Moskva: tendencii i problemy razvitija [Old and New Moscow: development trends and problems]. M.: Izd. IP Matushkina I.I. (in Russian)

Novikov A., Kotov E., Goncharov R., Nikogosjan K., Gorodnichev A. (2016) Moskva: kurs na policentrichnost'. Ocenka jeffektov gradostroitel'nyh proektov na policentricheskoe razvitie Moskvy [Moscow: course on polycentricity. Assessment of the effects of urban development projects on the polycentric development of Moscow]. M: Vysshaja shkola urbanistiki [Moskva Graduate School of Urban Studies]. (in Russian)

Rossman V. (2013) Stolicy. Ih mnogoobrazie, zakonomernosti razvitija i peremeshhenija [Capital Cities. Their diversity, patterns of development and movement]. Izdatelstvo Instituta Gaidara [Gaidar Institute Press]. (in Russian)

Teaford J.C. (1997) Post-suburbia: government and politics in the edge cities. Baltimore, MD: Johns Hopkins University Press.

Vendina O., Muratov A. (2013) Na puti k Superparku [On the way to Superpark]/Arheologija periferii. Sbornik statej [Archeology of the periphery. Digest of articles], M.: Strelka Institute, pp. 432-453. (in Russian) 